OPEN ACCESS

Edited by:

Attila Mócsai,

Semmelweis University, Hungary

Reviewed by:

Eva Borbely,

University of Pécs, Hungary

Guillaume Courbon,

Northwestern Medicine, United States Akhilesh Shakya,

Texas Tech University, United States

*Correspondence: Georgii B. Telegin telegin@bibch.ru

Specialty section: This article was submitted to Autoimmune and

Autoinflammatory Disorders, a section of the journal

Frontiers in Immunology

Received: 26 February 2021 Accepted: 28 April 2021 Published: 07 June 2021

Citation:

Telegin GB, Chernov AS, Kazakov VA, Romanova EA, Sharapova TN, Yashin DV, Gabibov AG and Sashchenko LP (2021) A 8-mer Peptide of PGLYRP1/Tag7 Innate Immunity Protein Binds to TNFR1 Receptor and Inhibits TNF $\alpha$-Induced Cytotoxic Effect and Inflammation.

Front. Immunol. 12:622471. doi: 10.3389/fimmu.2021.622471

\section{A 8-mer Peptide of PGLYRP1/Tag7 Innate Immunity Protein Binds to TNFR1 Receptor and Inhibits TNF $\alpha$-Induced Cytotoxic Effect and Inflammation}

\author{
Georgii B. Telegin ${ }^{1 *}$, Aleksandr S. Chernov ${ }^{1}$, Vitaly A. Kazakov ${ }^{1}$, Elena A. Romanova ${ }^{2}$, \\ Tatiana N. Sharapova ${ }^{2}$, Denis V. Yashin ${ }^{2}$, Alexander G. Gabibov ${ }^{3}$ and Lidia P. Sashchenko ${ }^{2}$ \\ ${ }^{1}$ Animal Breeding Facility, Branch of Shemyakin and Ovchinnikov Institute of Bioorganic Chemistry of the Russian Academy \\ of Sciences, Pushchino, Russia, ${ }^{2}$ Laboratory of Molecular Immunogenetics of Cancer, Institute of Gene Biology Russian \\ Academy of Science, Moscow, Russia, ${ }^{3}$ Laboratory of Biocatalysis, Shemyakin-Ovchinnikov Institute of Bioorganic \\ Chemistry RAS, Moscow, Russia
}

Search for novel regulatory protein fragments with potential functional roles is required both for understanding the immune response mechanisms and the development of targeted immunotherapy. Earlier we demonstrated that the PGLYRP1/Tag7 innate immunity protein can be regarded as an inhibitor of TNF $\alpha$ cytotoxic activity via the interaction with its TNF receptor 1 (TNFR1). A C-terminal peptide fragment 17.1 of the molecule is responsible for this function. In this study we have identified a minimal 8-mer region of this peptide (hereinafter $-17.1 \mathrm{~A}$ ) capable to bind to TNFR1. As a result of such interaction, the cytotoxic signals induced by this receptor are blocked. Also, this peptide demonstrates an anti-inflammatory activity in vivo in the complete Freund's adjuvant (CFA)-induced arthritis model in laboratory mice. Peptide $17.1 \mathrm{~A}$ is capable to reduce periarticular inflammation, inhibit the development of synovitis and exhibit a protective effect on cartilage and bone tissues. This peptide can turn out to be a promising medicinal agent for autoimmune arthritis and other diseases.

Keywords: mice, complete Freund's adjuvant, inflammation, arthritis, TNF $\alpha$, Tag7, 17.1 and 17.1A peptides

\section{INTRODUCTION}

Understanding the immune response mechanisms will help to develop effective treatments which can inhibit inflammatory processes. Typically, pro-inflammatory cytokines are responsible for the induction of inflammation (1). Multiple immune defense reactions start with inflammation. However, an overexpression of inflammatory cytokines can cause damage of body cells and tissues (2).

TNFo is a well-known example of the cytokine that can have two opposite functions (3). TNFo is released mainly by monocytes in response to the activation of the innate immunity TLR4 and TREM1 receptors localized on the surface of these cells. TNFo functional activity is mediated by interaction with its specific receptor TNFR1 which is present on the outer membrane of multiple 
cells. TNF $\alpha$ is necessary for the normal development of organisms (4). It contributes to antibacterial protection, facilitates proliferation of the lymphocytes and is able to kill the tumor cells. At the same time, a non-regulated increase in TNF $\alpha$ concentration can induce inflammatory processes causing such diseases as autoimmune arthritis, sepsis, and cachexia (5). A protective effect against TNF $\alpha$-mediated damages is realized in the body at least by the following two mechanisms: decreasing the concentration of this cytokine or inhibiting its functional activity. Specific antibodies binding to TNF $\alpha$ with the formation of inactive complex are currently widely used (6). The use of proteins or their fragments that interact with TNFR1 and impede the TNF $\alpha$ binding to this receptor can be considered as a promising way for reducing TNF $\alpha$ activity.

We demonstrated that the PGLYRP1 (PGRP-S, Tag7) protein, whose gene was also found in mammalian species, competes with TNF $\alpha$ for binding with TNFR1 (7). An innate immunity protein, Tag7, is commonly found in insects, mollusks, mammals (8). This protein is capable to activate the mechanisms of antibacterial protection, and its complex formed with $\mathrm{Ca}^{2}$ ${ }^{+}$-binding protein Mts1 can induce chemotaxis of the immune cells $(9,10)$. Through its binding to the TREM1 receptor, Tag7 can induce immune response effective against the tumor cells which have lost the MHC complex proteins on the cell surface (11). In its complex with the heat shock protein Hsp70 it induces TNFR1- mediated tumor cell death (12). Recently we identified a 17-mer peptide fragment of Tag7 (hereinafter - 17.1) capable to bind to TNFR1 and inhibit the cytotoxic effect of the Tag7Hsp70 complex and TNF $\alpha$-induced cell death. Also, peptide 17.1 demonstrated a protective effect in CFA-induced autoimmune arthritis (13). Speaking about approaches that impede the development of inflammatory processes, it seems fair to use agents derived from proteins or their fragments with a lower molecular weight. The shortest peptides are considered as the most promising products in view of a simple manufacturing process and their beneficial bioavailability (14).

The objectives of this study were to identify a minimal fragment of the earlier described peptide 17.1 which is capable to bind to TNFR1 and to compare the inhibition of the TNF $\alpha$ functional activity mediated by 17.1 peptide and its shortened peptide in a cell line, as well as to assess its potential for inhibiting inflammation in (CFA)-induced autoimmune arthritis model in laboratory mice.

\section{MATERIALS AND METHODS}

\section{Cell Lines}

In this study, we used L929 cells cultured in DMEM (Gibco, USA) supplemented with $2 \mathrm{mM} \mathrm{L-glutamine,} 10 \%$ fetal calf serum (Gibco, USA), penicillin and streptomycin, in a humidified $5 \% \mathrm{CO}_{2}$ atmosphere at $37^{\circ} \mathrm{C}$.

\section{Proteins and Antibodies}

IgG autoantibodies were obtained from the blood serum of donors with systemic lupus erythematosus as described in (15).
Recombinant Tag7, Hsp70 were produced as described earlier (12). Recombinant rhTNF $\alpha$ (SigmaAldrich, USA) and polyclonal antibodies to TNFR1 (Santa-Cruz, USA) were used in the study. Peptides 17.1 and 17.0 were obtained as described in (13). An order for chemical synthesis of peptide 17.1A was placed with Synpeptide Co Ltd.

\section{Biotinylating, Affinity Chromatography, Immunoadsorption, and Immunoblotting}

Biotinylation of peptides was performed as described earlier (16). sTNFR1 was conjugated to CN-Br-activated Sepharose (SigmaAldrich, USA) according to the manufacturer's protocol. Biotinylated peptides were adsorbed onto the TNFR1 column. The column was washed with PBS alone and further with PBS/ $0.5 \mathrm{M} \mathrm{NaCl}$, and then eluted with $0.25 \mathrm{M}$ triethylamine ( $\mathrm{pH} 12$ ). The eluted material was separated using denaturing polyacrylamide gel electrophoresis (PAGE) according to the technique described in (12). The biotinylated products were visualized in the nitrocellulose membrane with streptavidinconjugated horseradish peroxidase (HRP) and then with an ECL Plus ${ }^{\circledR}$ kit (GE Healthcare, USA). Chemiluminescence was detected using iBright (Thermofisher, USA).

\section{Cytotoxic Activity}

L929 cells were incubated in a 96-well plate, $3 \times 10^{4}$ cells per well in DMEM supplemented with $2 \mathrm{mM}$ L-glutamine, and $10 \%$ fetal calf serum. Cytotoxicity was measured after incubation with antibodies in DMEM (without serum) for 3 and $24 \mathrm{~h}$ in a humidified $5 \% \mathrm{CO}_{2}$ atmosphere at $37^{\circ} \mathrm{C}$. Cells were stained with Trypan Blue and coded samples were counted under the microscope, at least 100 cells scored for each group. Cytotoxicity was calculated as Cytotoxity $=\frac{(S t-S p)}{(T-S p)} \times 100 \%$, where $S t$ is the number of stained cells; $S p$, spontaneously stained cells; $T$, total cells. In some cases (Figure 3) cell death was determined with the CytoTox 96 Assay kit (Promega); the discrepancy between the two assays never exceeded 5\% (12).

\section{Mice}

Female CD-1 mice SPF-category with average weight ( \pm SEM) of $26.9 \pm 2.40 \mathrm{~g}$ were used in this study. The animals were bred and housed in the Pushchino Animal Breeding Facility that had been accredited by AAALACi (Unique Research Unit "Biomodel" of the Institute of Bioorganic Chemistry, Russian Academy of Sciences). All the experiments and manipulations performed were approved by the Institutional Animal Care and Use Committee (IACUC) (no. 713/20 of 06/08/20). Arthritis was induced by injection of $40 \mu \mathrm{L}$ complete Freund's adjuvant (CFA) into the left ankle joint of mice according to the technique described earlier (13). The animals were randomly assigned into five different groups of ten animals per group $(n=10)$ : group I control, no CFA injection (Normal saline + Normal saline); group II - CFA-control (CFA + Normal saline); group III, CFA with treatment of the peptide $17.1 \mathrm{~A}(120 \mu \mathrm{g}$ per mouse); group IV - CFA with treatment of the non-steroid anti-inflammatory drug "Norocarp" (Carprofen 5\%) (120 $\mu$ g per mouse); and group $\mathrm{V}$ - CFA with treatment of the peptide 17.1 (120 $\mu \mathrm{g}$ per mouse). Peptides and "Norocarp", dissolved in $100 \mu \mathrm{L}$ of normal saline, 
were intravenous injected after $24 \mathrm{~h}$ the induction of inflammation. Rectal temperature and hind paws (on the lateral side of the foot) temperature was measured on days 1 , $3,5,10$ and 21 of the experiment. Hind paw edema was measured on days $1,5,21$.

\section{Measurement of Body and Hind Paw Temperature}

A portable digital thermometer (ATK-610B, ATP Instruments, USA) was used for measuring temperature. Body temperature was checked with a rectal probe. Temperature at the lateral side of the foot was measured with thermocouple probes. Temperature differences between the left (with induced arthritis) and the right (intact) paws were determined by the formula:

$$
\Delta t=t_{1}-t_{r},
$$

where $t_{1}-$ temperature of the left paw, $t_{r}-$ temperature of the right paw.

\section{Rating Scale for Assessing Paw Edema in Mice With Arthritis}

After CFA injection, inflammation and edema were assessed in each of the animals. Then, the results were summarized using a rating scale (score) (17):

$0=$ normal,

$1=$ mild but visible redness and edema of the ankle or obvious redness and swelling, limited by individual toes, regardless of the number of affected toes;

2 = moderate ankle redness and swelling;

3 = severe redness and swelling of the entire paw, including toes;

$4=$ maximum extent of paw inflammation affecting several joints and all toes.

\section{Assessment of Paw Inflammation With Micrometer}

The thickness of the paw edema was measured using a micrometer (MK-50-75, Russia) $1 \mathrm{~h}$ before CFA-induced arthritis and 1, 5, and 21 days after treatment. All the assessments were performed by the same investigator in order to reduce any potential inter-operator differences.

The anti-inflammatory activity of peptides and Norocarp to inhibit hind paw swelling was calculated as reported previously by Samud et al. (18) as follows:

$$
\% \text { Infammation }=((A-B) / B) \times 100,
$$

where $\mathrm{A}=$ measurement of hind paw thickness after CFA induced arthritis and $\mathrm{B}=$ initial measurement of hind paw thickness before CFA - induced arthritis.

\section{Histopathology}

Mice were euthanized at days 3,10 or 21 to perform pathomorphological study of ankle joint specimens. The specimens of mouse left ankle joint (the tarsus, metatarsus and the part of the ankle) were fixed with $10 \%$ neutral buffered formalin
$(\mathrm{pH}=7.4)$ for 5 to 7 days and then decalcified in Trilon $\mathrm{B}$ for 10 to 12 days at room temperature. Once a satisfactory decalcification of bone and cartilage tissues was reached, sagittal cross-sections of the joint specimens without skin dissection were prepared, washed in running water, dehydrated in ascending ethyl alcohol series and embedded in paraffin. Paraffin cross-sections ( $4-5 \mu$ m thick) were stained with hematoxylin and eosin and analyzed, using light microscopy on a AxioScopeA1 microscope (CarlZeiss, Oberkochen, Germany). The images of histological slides were recorded using a high-resolution camera Axiocam 305 color (CarlZeiss, Germany) and software ZEN 2.6 lite (Carl Zeiss, Germany). The histological study included the assessment of the following morphological characteristics: intensity of infiltration of WBC into the synovial membrane (synovitis), synovial hyperplasia, articular cartilage damage, and destruction of bone tissue.

The severity of various arthritis manifestations was assessed semi-quantitatively according to the scale described in article Andreev-Andrievskiy et al., 2016. Five high-power magnification fields (HMF) were scored for each animal. Synovial inflammation was scored based on the amount of infiltrating mononuclear cells as follows: 0 , absent; 1 , mild (1-10\%); 2, moderate (11-50\%); 3, severe (51-100\%). Synovial hyperplasia was scored as 0 , absent; 1 , mild (three to four layers for knee and two layers for paw); 2 , moderate (five to six layers for knee and three and more layers for paw); 3, severe (more than six layers for knee and three layers for paw). Cartilage erosion was evaluated based on the fraction of the cartilage surface that was erosed: 0 , absent; 1 , mild (1-10\%); 2 , moderate (10$30 \%$ ); 3 , severe (more than $30 \%$ ). Bone erosion was scored as 0 , none; 1, minor erosion(s) observed only at HMF; 2, moderate erosion(s) observed at low magnification; 3 , severe transcortical or subtranscortical erosion(s) (19).

\section{Statistical Analysis}

All data were calculated from at least three independent biological replicates as stated in the legends of the corresponding figures. Testing for significant differences between treatment and control was carried out with MathCad software (PTC, Cambridge, MA). The statistical test carried out is stated in the legend of the corresponding table or figure, employing t-tests in comparisons between treatment and control and two-way ANOVA in comparisons between control and several compounds. For analysis of the body temperature levels and the severity of inflammation and edema of hind limbs in mice with arthritis (score), the data are presented as the means \pm SEM measured for each point. Statistically significant differences were determined using t-tests with in comparisons between treatment and nontreatment $(\mathrm{CFA}+\mathrm{NS})$ and in comparisons between data from all time-point the same group with baseline.

\section{RESULTS}

\section{Peptide 17.1A Binds to TNFR1-Receptor and Inhibits TNFR1-Mediated Cell Death}

During our earlier study, we demonstrated that the peptide fragment of Tag7 protein (peptide 17.1) localized at the 
C-terminus of protein molecule was inhibiting the TNFR1mediated cytotoxicity. To elucidate a minimal amino acid sequence, determining the interaction between Tag7 and the TNFR1 receptor, the C-terminus fragment of peptide 17.1 was synthesized. The synthesized peptide containing eight aminoacid residues (RSNYVLKG) was designated as 17.1A. Next, we investigated a potential 17.1A binding to TNFR1 and its ability to inhibit the cytotoxic activity.

At the first stage of our study when the interaction between 17.1A with TNFR1 receptor was investigated, affine chromatography was performed using a column with TNFRI immobilized on CN-Br-sepharose (Figure 1, Supplemental Figure 1).

One can see that peptide $17.1 \mathrm{~A}$ is present in the eluate from the affinity column. A control peptide 17.0, the N-terminus molecule fragment, was not found in the eluate from this column.

Thus, it is suggested that peptide $17.1 \mathrm{~A}$ is a minimal region of peptide 17.1 required for protein Tag7 binding to the TNFR1 receptor.

During the second stage of our study, we verified the impact of this binding on the TNFR1-mediated induction of cell death. We demonstrated earlier that in addition to TNF $\alpha$, there could be other TNFR1 ligands, such as the Tag7-Hsp70 cytotoxic complex and DNA-binding antibodies (20).

For this purpose, we investigated the effect of peptide $17.1 \mathrm{~A}$ on the cytotoxic activity induced by the aforementioned three ligands. Taking into consideration the TNFR1 ability to induce two cytotoxic processes (a rapidly developing apoptosis and a slower necroptosis), we studied the inhibiting effect of peptide 17.1A on apoptotic and necroptotic cytotoxic processes occurring after 3 and 24 h, respectively (Figure 2).

The inhibition of cytotoxic activity of TNF $\alpha$, the Tag7-Hsp70 complex and autoimmune antibodies with anti-TNFR1 antibodies matches our earlier findings showing that all the three investigated inducers cause TNFR1-mediated cell death (13).

As one can see, peptide 17.1 is inhibiting not only the cytotoxic activity of TNF $\alpha$ and the Tag7-Hsp70 complex (as demonstrated earlier), but also the cytotoxic activity of DNAbinding autoantibodies. When a control peptide 17.0 was used, no evidences of cytotoxic activity reduction were found. In all cases the cytotoxicity was suppressed by peptide 17.1A. Hence, this particular fragment of peptide 17.1 is required for binding to TNFR1 and inducing cell death.

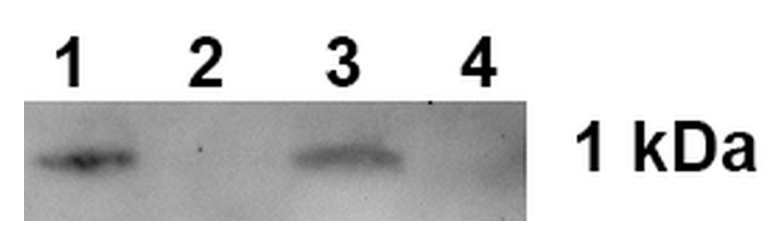

FIGURE 1 | Peptide 17.1A binding to sTNFRI immobilized on CN-Br-sepharose. 1 - control 17.1A, 2 - column washing before the elution, 3 - elution of the sTNFR1-bound material, 4 - peptide 17.0 elution from the column.

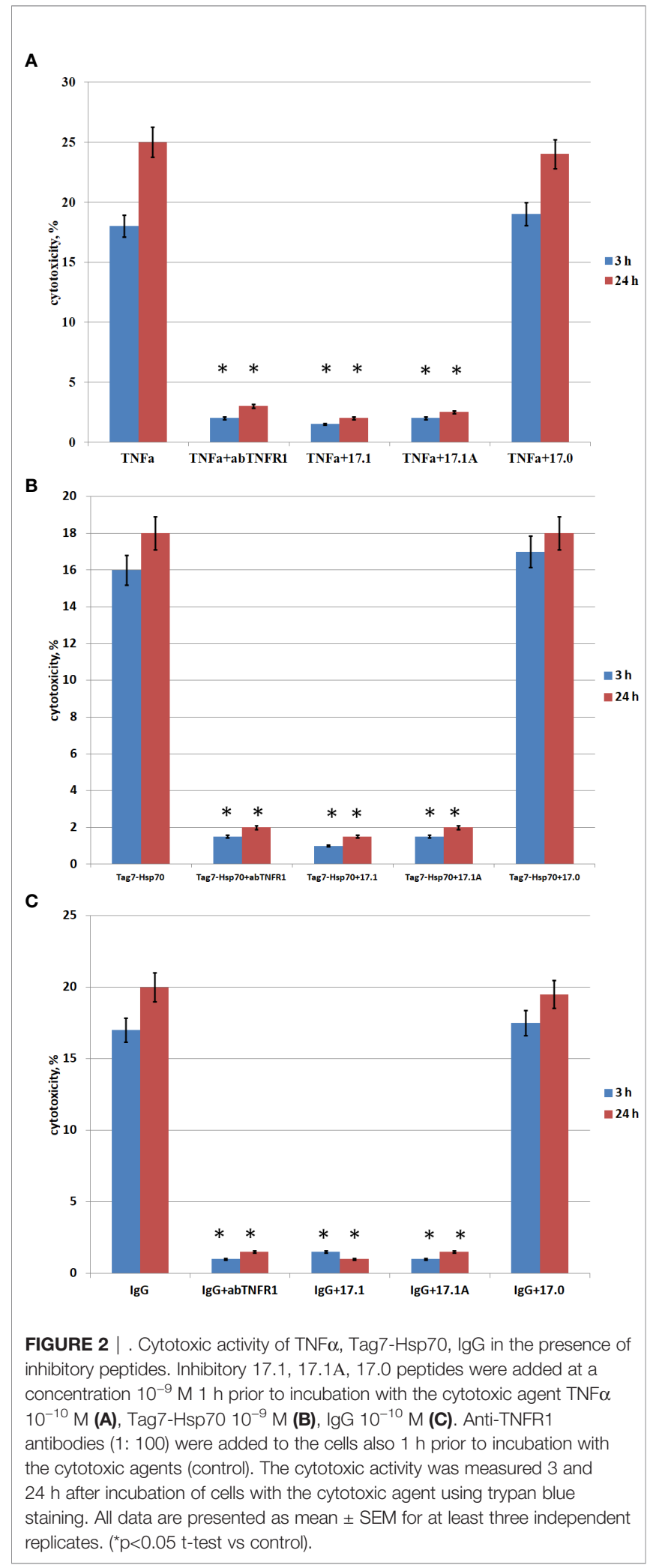

To compare the specificity of peptides 17.1 and $17.1 \mathrm{~A}$ binding to the TNFR1 region which interacts with ligands, variations in the inhibition of TNF $\alpha$ cytotoxic activity were investigated for 
different concentrations of these peptides. For this purpose, the peptides were preincubated with target cells, then TNF $\alpha$ was added to measure its cytotoxic activity (Figure 3 ).

One can see that the inhibition of TNF $\alpha$ cytotoxicity is dosedependent, and both peptides have the inhibitory effect within the same range of concentrations. The inhibition reached half of its efficiency when the ratio peptide $17.1 / \mathrm{TNF} \alpha$ was equal to $2 / 1$, and when the ratio peptide $17.1 / \mathrm{TNF} \alpha$ was $3 / 1$, the values $\mathrm{IC}_{50}-$ $0.5 \mathrm{nM}$ for 17.1 and $0.3 \mathrm{nM}$ for $17.1 \mathrm{~A}$ were comparable. These data suggest that both peptides have a similar affinity to the TNFR1 region interacting with ligands. It can be assumed that peptide $17.1 \mathrm{~A}$ is a fragment of peptide 17.1 responsible for binding to the receptor.

\section{Peptide 17.1A Reduces Inflammation and Edema in the Model of CFA-Induced Arthritis in Mice}

Using a rating scale for assessing the development of paw edema in the arthritis model in mice, it was established that a single injection of either peptide 17.1 , or peptide $17.1 \mathrm{~A}$ resulted in a significant reduction of the CFA-induced hind paw edema as compared with non-treated animals (Figure 4). When peptide $17.1 \mathrm{~A}$ was used the damage severity decreased already by day 3 (score 2.31). A similar effect was observed for Norocarp drug (score 2.43). Out of the two peptides, 17.1 exhibited a lower antiedema effect (2.7 score by day 3 ). The maximum score of the hind paw edema was found in the group receiving CFA + normal saline (score 2.9). For intact animals a 0 score was recorded, using the above rating scale.

Table 1 show the effect of Norocarp, peptide 17.1 and 17.1A, on hind paw edema treatment 1,5 , and 21 days after the CFA induced arthritis. Treatment of peptide 17.1 and 17.1A produced a significant $(\mathrm{P}<0,05)$ reduction in the paw edema evaluated using a micrometer. These data correlate with results obtained

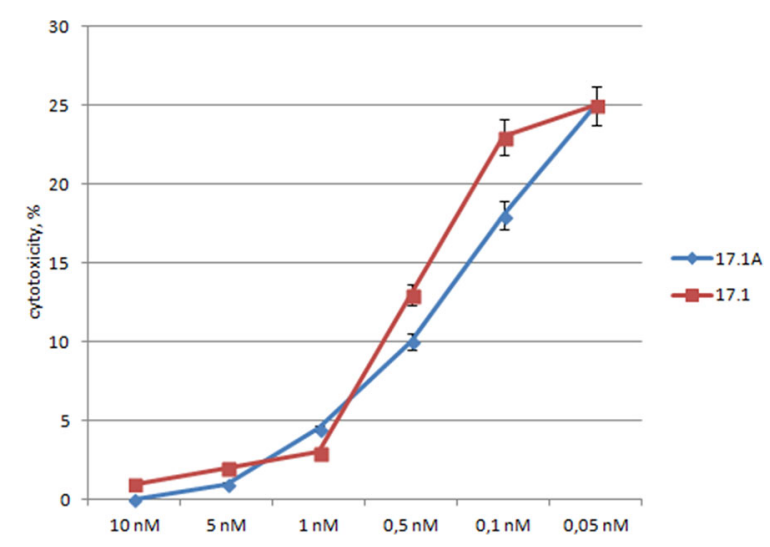

FIGURE 3 | The relationship between the cytotoxic activity and the concentrations of inhibitory peptides. Inhibitory 17.1 and 17.1A peptides in preset concentrations were added $1 \mathrm{~h}$ prior to incubation with TNF $\alpha\left(10^{-10} \mathrm{M}\right)$. The cytotoxic activity was measured $24 \mathrm{~h}$ after cell incubation with a cytotoxic agent. All data are presented as mean \pm SEM for at least three independent replicates. during the visual examination of the mice paws by «Rating Scale for Assessing paw Edema».

An increased body temperature is one of the typical signs of inflammation, including rheumatoid arthritis in rats $(21,22)$. We assessed the total body temperature and compared the hind paw temperature (with and without induced inflammation) in animals receiving normal saline, Norocarp drug and peptides 17.1 и 17A.

As shown in Figure 5, in mice with the CFA-induced arthritis the body temperature increased from $37.8^{\circ} \mathrm{C}$ to $38.5^{\circ} \mathrm{C}$ when they received normal saline. At the same time, after injection of studied peptides 17.1 and $17.1 \mathrm{~A}$ the body temperature was decreasing significantly during the first 10 days after inflammation induction (Figure 5). A similar effect was observed in mice treated for comparison with Norocarp drug. By day 21 of the experiment, the body temperature in mice from all groups returned to the normal range (day 0 level).

Comparison of the hind paw temperatures demonstrated that after CFA injection the temperature increased topically, at the site of inflammation (Figure 6). Thus, at day 1 the temperature difference between the intact and affected paws was approx. $2.2^{\circ} \mathrm{C}$. Similarly to Norocarp drug, short peptide $17.1 \mathrm{~A}$ reduced the temperature difference as early as by day 3 of the experiment (Figure 6). However, by day 3 the results in the group of animals treated with a long peptide 17.1 were comparable with those in the group receiving normal saline. Further observations showed that the use of studied peptides resulted in a continuous $\Delta t$ reduction through day 21 of the observation period.

It is worth noting that used for comparison Norocarp drug caused a temporary temperature drop during the first 3 days. Later, up to day $10 \Delta \mathrm{t}$ was increasing that could be explained by a complete drug clearance from the body and the continuing CFA inflammation-inducing effect. At the same time, the studied peptides demonstrated a prolonged anti-inflammatory activity.

\section{Peptide 17.1A Exhibits an Anti- Inflammatory and Protective Effect on the Cartilage and Bone Tissues in the Model of CFA-Induced Arthritis}

Next, a protective anti-inflammatory effect was compared for the studied peptides in the model of CFA-induced arthritis.

The development of severe periarticular inflammation (periarthritis with exudation) due to infiltration of segmented neutrophils with a moderate number of lymphocytes and macrophages (the proportion of the latter was gradually increasing during the late period of observation) into soft tissues was found in all examined specimens taken at different dates of the observation period in the model of CFA-induced arthritis. In most cases, the inflammatory process was described as one or more sites of inflammation in several areas of the paw, or, more rarely, as diffuse inflammation. The synovial membrane of the ankle, tarsal and metatarsal joints was affected by the pathological process, since the joints were located closely to the WBC infiltration sites.

It was always associated with the inflammatory infiltration expansion from soft tissues to the synovial membrane. Usually, such inflammatory process affected the synovial membrane of 


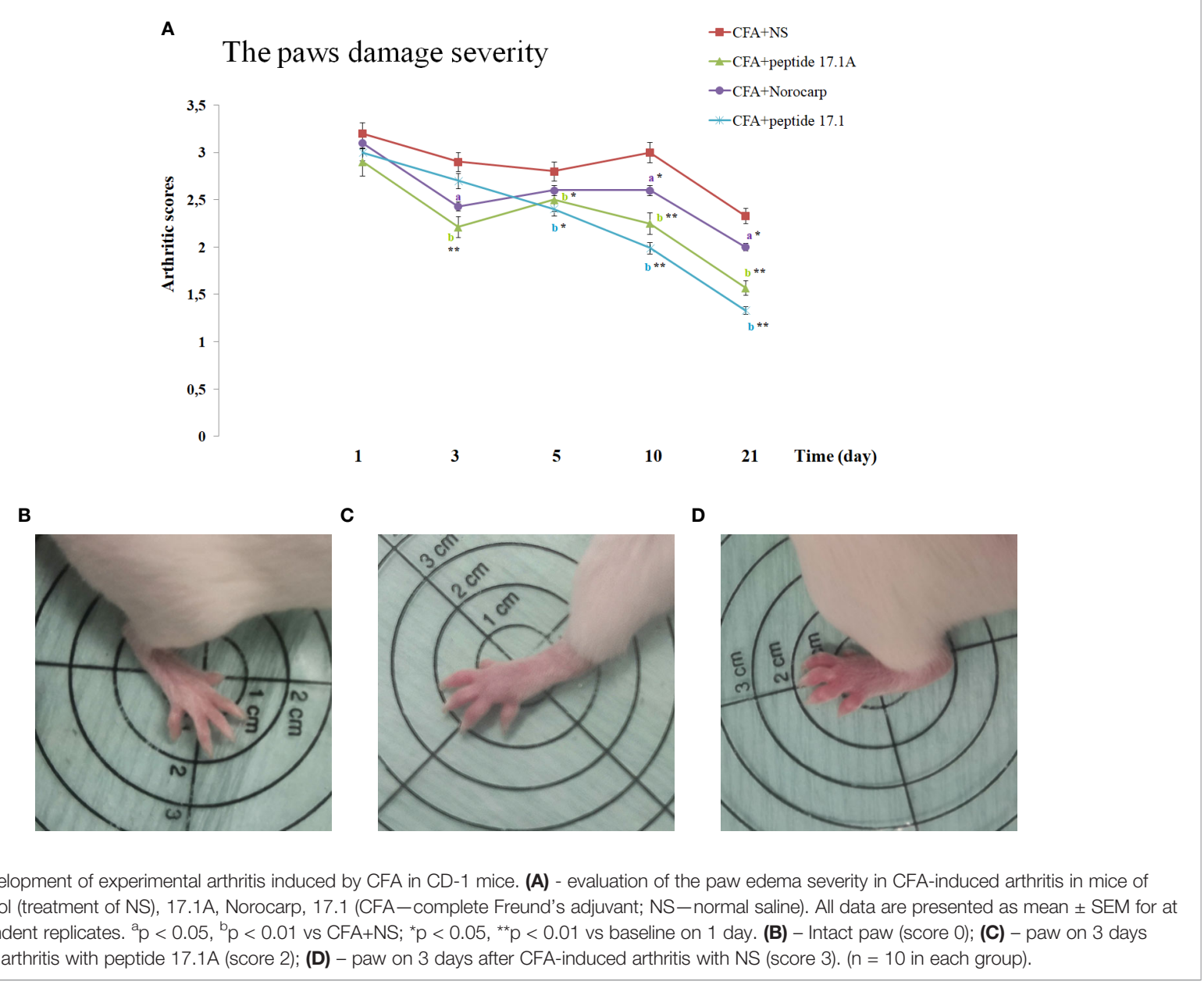

TABLE 1 | The effect of administration of drugs on hind paw edema measured using the micrometer method.

\begin{tabular}{lccc}
\hline Compound & \multicolumn{3}{c}{ Inflammation } \\
\cline { 2 - 4 } & $\mathbf{1}$ day & $\mathbf{5}$ day & $\mathbf{2 1}$ day \\
\hline CFA+NS & 51,76 & 47,64 & 43,81 \\
CFA+peptide 17.1A & $46,42^{*}$ & $38,17^{\star}$ & $24,12^{\#}$ \\
CFA+ Norocarp & 49,12 & 45,32 & $37,33^{\star}$ \\
CFA+peptide 17.1 & $44,54^{\star}$ & $29,39^{\star}$ & $17,44^{\#}$ \\
\hline
\end{tabular}

The values are presented as \% of the mean. Significant difference $\left({ }^{*} P<0.05\right.$; $\left.{ }^{\#} P<0.01\right)$ between treated $(17.1,17.1 \mathrm{~A}$, Norocarp) and non-treated groups ( $n=10$ in each group).

the ankle and tarsal joints with exudate cells appearing in the joint space. However, only mild destructive damages were found in the articular hyaline cartilage, typically manifested as karyolysis in individual chondrocytes and within the chondrin balls. The signs of cartilage destruction, probably of mechanical or trophic origin (without related inflammatory lesions), were observed in some animals. Destruction of bone tissue in all reported cases was not associated with cartilage damage. It related only to the articular element localization nearby the inflammation site in soft tissues and always started from periosteum. Thus, the most common finding in mice

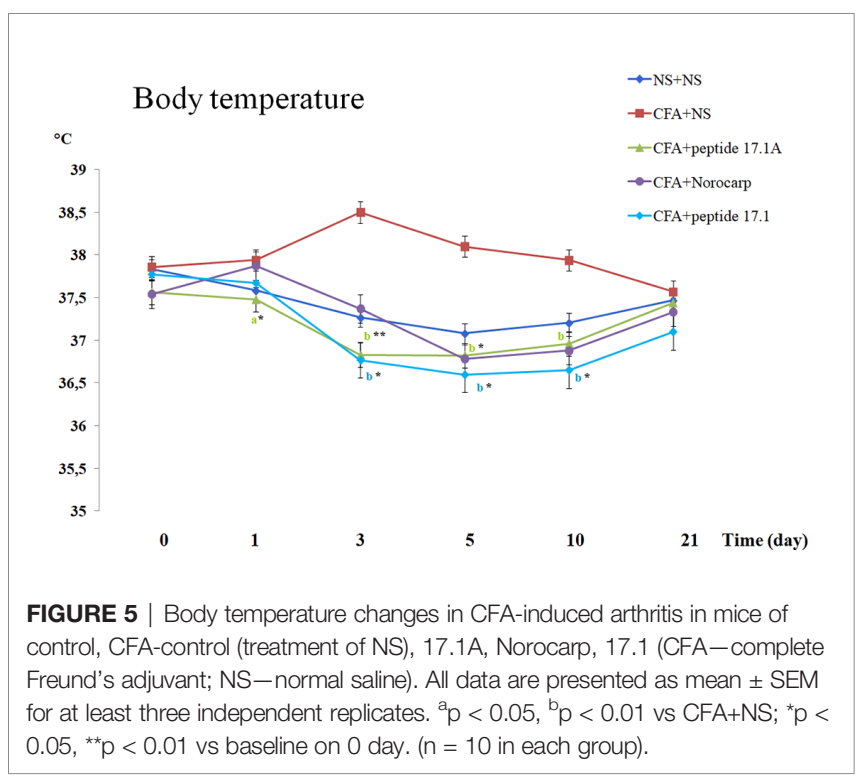

comprised severe lesions of periarticular tissues (exudative periarthritis) with a varying involvement of joint structures 


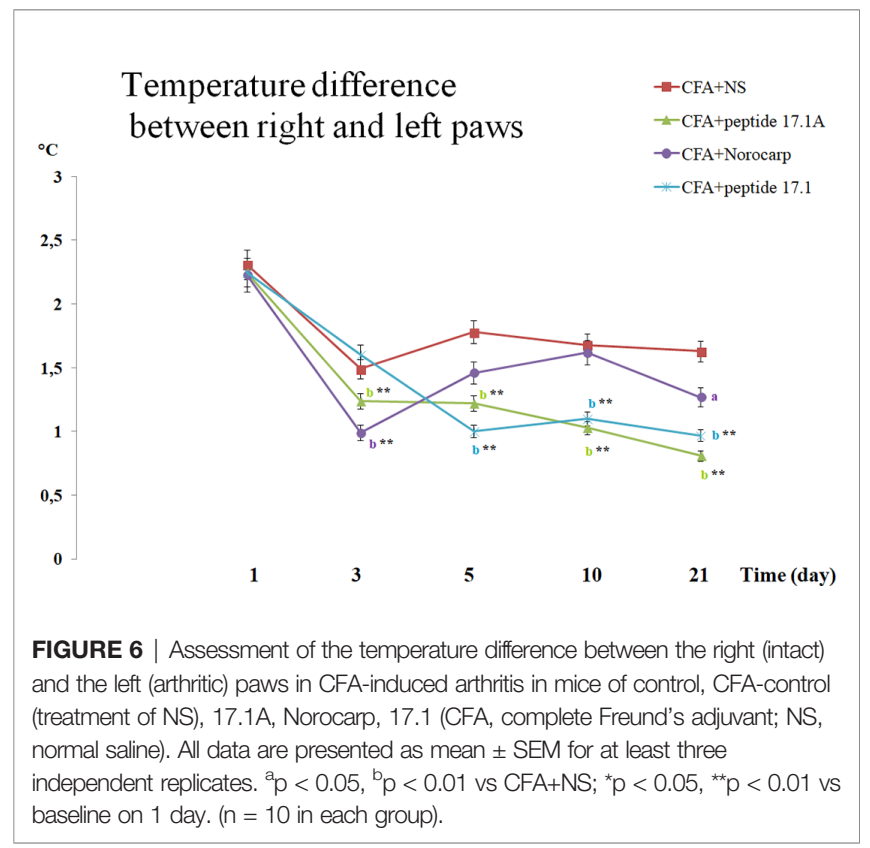

(arthritis). Data for different dates of the observation period are summarized in Table 2.

At days 3, 10 (Figure 7A) and 21 (Figure 8A) in mice receiving normal saline no pathomorphological changes were found in soft tissues surrounding the joint or intra-articular structures.

At day 3, intense infiltration of white blood cells into tissues surrounding the joint (score 2) accompanied by synovitis (score 2) and mild synovial hyperplasia (score 1) was reported for all mice receiving normal saline after CFA injection. Damages of the articular hyaline cartilage or destruction of bone tissues surrounding the inflammation site were not observed. In the model of CFA-induced arthritis at day 3 no considerable positive trend in the course of periarticular inflammation or synovitis was noted for mice treated with Norocarp. Injections of peptides 17.1 and $17.1 \mathrm{~A}$ neither improved the general course of inflammation by day 3 of the observation period.

At day 10 of the study, in mice receiving normal saline in the model of CFA-induced arthritis the mean scores of periarticular inflammation and WBC infiltration into synovial membrane reached their peaks (score 3.0); synovial hyperplasia, articular cartilage damage and destruction of bone tissue (score: 2.0, 1.0, and 2.0, respectively) were also characterized by a tendency towards increasing severity (Figure 7B). An anti-inflammatory effect in mice treated with Norocarp was only moderate as assessed by the severity of exudative periarthritis (2.5 score), synovitis and synovial hyperplasia (2.0 and 1.0 score, respectively) (Figure 7D). The severity of destruction of skeletal structures at day 10 after induction of inflammation was assessed in articular cartilage (1.0 score) and bone tissue (1.5 score). It was demonstrated that peptide 17.1A (Figure 7C) had an intermediate anti-inflammatory effect in soft tissues as compared to Norocarp and control (normal saline). At the same time, according to the rating scale the damage of cartilage tissue was 0.4 score and bone tissue destruction - 1.2 score. Even more encouraging results were obtained for mice treated with peptide 17.1, as shown by the following indicators: infiltration of WBC into the synovial membrane (mean score 1.5); the minimal destruction of bone tissue (score 1.0); and, the absent articular cartilage damage (Figure 7E).

The most illustrative findings were reported at day 21 of the study. In mice receiving normal saline in the model of CFA-induced arthritis the mean scores of periarticular inflammation and WBC infiltration into synovial membrane stayed at the level of day 10 (Figure 8B). The highest anti-inflammatory activity within this time period was demonstrated after injections of peptide 17.1A (Figure

TABLE 2 | Summary table of the assessment of periarticular inflammation, synovitis, synovial hyperplasia, destructive damages of articular cartilage and bone tissue of the left ankle joint in the model of CFA-induced arthritis after injections of tested agents (score mean $\pm \mathrm{SEM}$ ).

\begin{tabular}{|c|c|c|c|c|c|c|}
\hline \multirow[t]{2}{*}{ Days after CFA-induced arthritis } & \multirow[t]{2}{*}{ Study groups } & $\begin{array}{l}\text { Periarticular } \\
\text { inflammation }\end{array}$ & Synovitis & $\begin{array}{c}\text { Synovial } \\
\text { hyperplasia }\end{array}$ & Articular cartilage damage & Destruction of bone tissue \\
\hline & & \multicolumn{5}{|c|}{ Score } \\
\hline \multirow{3}{*}{ Day 3} & $\mathrm{CFA}+\mathrm{NS}$ & 0 & 0 & 0 & 0 & 0 \\
\hline & CFA - 17.1A & $2.00 \pm 0.20$ & $2.00 \pm 0.19$ & $1.00 \pm 0.11$ & 0 & 0 \\
\hline & CFA+ Norocarp & $2.00 \pm 0.10$ & $2.00 \pm 0.25$ & $1.00 \pm 0.10$ & 0 & 0 \\
\hline \multirow[t]{6}{*}{ Day 10} & NS+NS & & & & & \\
\hline & CFA+NS & 0 & 0 & 0 & 0 & 0 \\
\hline & $\mathrm{CFA}+17.1 \mathrm{~A}$ & $3.00 \pm 0.14$ & $3.00 \pm 0.30$ & $2.00 \pm 0.22$ & $1.00 \pm 0.11$ & $2.00 \pm 0.16$ \\
\hline & CFA+ Norocarp & $2.80 \pm 0.20$ & $2.20 \pm 0.17^{b}$ & $1.60 \pm 0.21$ & $0.40 \pm 0.12^{b}$ & $1.20 \pm 0.15^{b}$ \\
\hline & $\mathrm{CFA}+17.1$ & $2.50 \pm 0.16^{a}$ & $2.00 \pm 0.17^{\mathrm{a}}$ & $1.00 \pm 0.13^{a}$ & $1.00 \pm 0.07$ & $1.50 \pm 0.13$ \\
\hline & & $2.50 \pm 0.19^{b}$ & $1.50 \pm 0.09^{b}$ & $1.00 \pm 0.11^{b}$ & 0 & $1.00 \pm 0.26^{b}$ \\
\hline \multirow{2}{*}{ Day 21} & CFA+ 17.1 & $2.33 \pm 0.24^{a}$ & $2.00 \pm 0.21^{b}$ & $1.00 \pm 0.20$ & $1.00 \pm 0.10$ & $1.33 \pm 0.19^{b}$ \\
\hline & & $2.67 \pm 0.30^{a}$ & $2.33 \pm 0.26^{a}$ & $1.33 \pm 0.18$ & $1.00 \pm 0.09$ & $2.33 \pm 0.17$ \\
\hline
\end{tabular}

Significant difference $\left.{ }^{p} p<0.05 ;{ }^{b} p<0.01\right)$ between treated $(17.1,17.1 \mathrm{~A}$, Norocarp) and non-treated groups $(n=10$ in each group). 
8C) and Norocarp (Figure 8D): periarticular inflammation (score 2.29 and 2.33, respectively); synovitis (2.0 score); synovial hyperplasia and articular cartilage damage ( 0.71 and 1.0 score, respectively); destruction of bone tissue (1.43 and 1.33 score, respectively).

Within this time period, peptide 17.1 was less effective than peptide 17.1A or Norocarp (Figure 8E). However, there was a mild positive trend in the course of exudative periarthritis and arthritis as compared to mice receiving normal saline.

\section{DISCUSSION}

Two significant results were obtained in this study: (1) a minimal amino acid sequence ( 8 a.a.) of the innate immunity protein Tag7 responsible for binding to the cytokine $\mathrm{TNF} \alpha$ receptor, TNFR1, was identified; (2) it was demonstrated that this peptide fragment exhibits an anti-inflammatory and protective activity against TNF $\alpha$-mediated cytotoxic effects.

Earlier we demonstrated that Tag7 protein in its complex with the heat shock protein Hsp70 induces tumor cell death mediated through the TNFR1 receptor. It turned out that the cytotoxic protein complex components exhibit different types of functional activity: Tag 7 is required for the interaction with the TNFR1 receptor and the cytotoxic complex binding to the membrane; Hsp70 is involved in inducing cytotoxic signal. When Hsp70 is absent, Tag7 is unable to induce cell death and acts as an inhibitor of cytotoxic activity of the Tag7-Hsp70 complex as well as other TNFR1 ligands, such as TNF $\alpha$ and autoantibodies (23).

Recently we found out that a Tag7 fragment responsible for the cytotoxic activity resides in the $\mathrm{C}$-terminus of the protein molecule. Isolated peptide 17.1 has two functions: it is able to inhibit the cytotoxic effect by its interaction with TNFR1 and cause cell death in its complex with Hsp70. In this study, we identified a fragment of peptide 17.1, designated 17.1A, responsible for binding to TNFR1. It is worth noting that inhibition of the TNFR1-induced cytotoxicity in the presence of peptide $17.1 \mathrm{~A}$ is not dependent on the inducer type. This novel peptide inhibits the cytotoxic effect of TNF $\alpha$, the Tag7-Hsp70 complex and DNA-binding antibodies. Probably, peptide 17.1A has affinity to the TNFR1 region, which acts as a core of this receptor binding to multiple ligands.

Once the inhibition of the TNF $\alpha$ cytotoxic activity by peptide 17.1 had been elucidated, the effect of this peptide on generalized inflammatory processes, including those induced by this cytokine, was studied. Protective activity of peptide 17.1 in the model of CFA-induced arthritis was described earlier (13).

In this study, we confirmed the inhibiting activity of peptide 17.1 and demonstrated that its shortened fragment, peptide $17.1 \mathrm{~A}$, can be also characterized as an inhibitor of TNF $\alpha$-dependent arthritis. It is suggested that infiltration TNF $\alpha$-secreting macrophages into joint capsule is a starting point in the onset of arthritis followed by systemic inflammation and progression of the disease (24).

It can be assumed that, besides inducing inflammatory processes, TNF $\alpha$ can cause death of articular cells carrying the TNFR1 receptors, thus enhancing the destructive effect of the disease. There are multiple models of arthritis dependent on increase in TNF $\alpha$ concentration, including the model of CFA-induced arthritis.

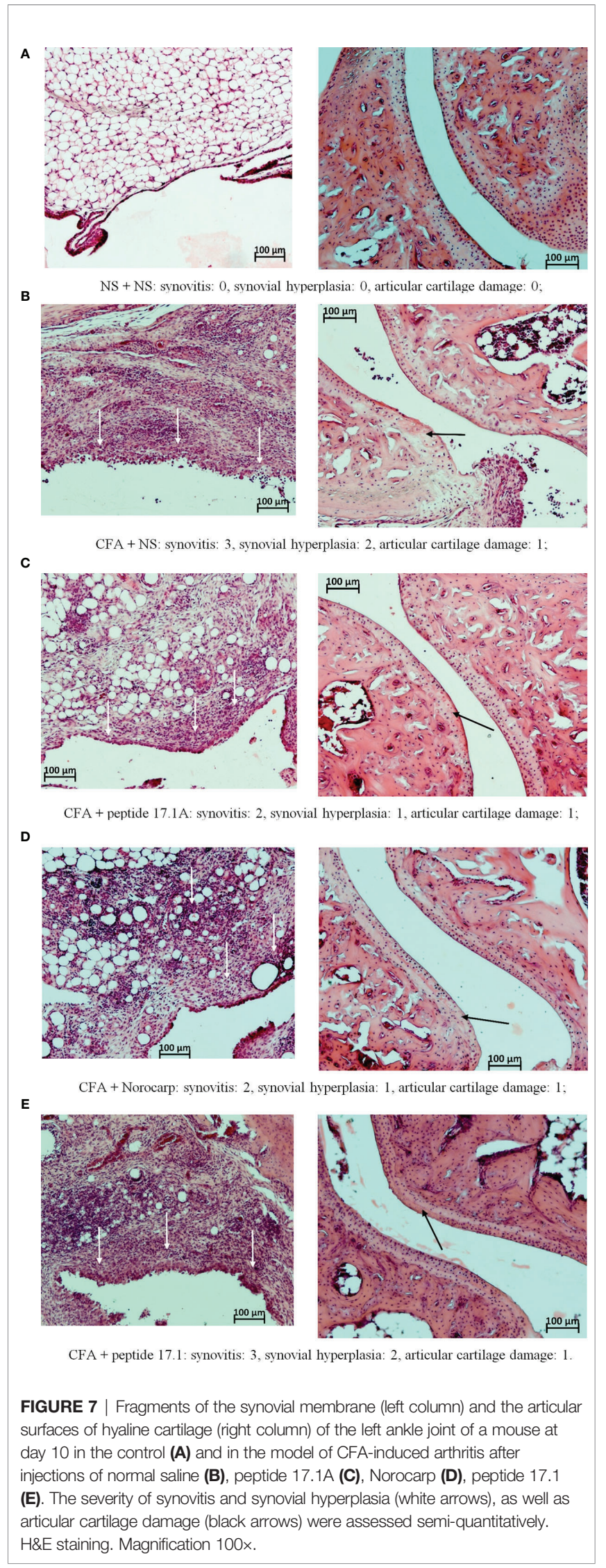




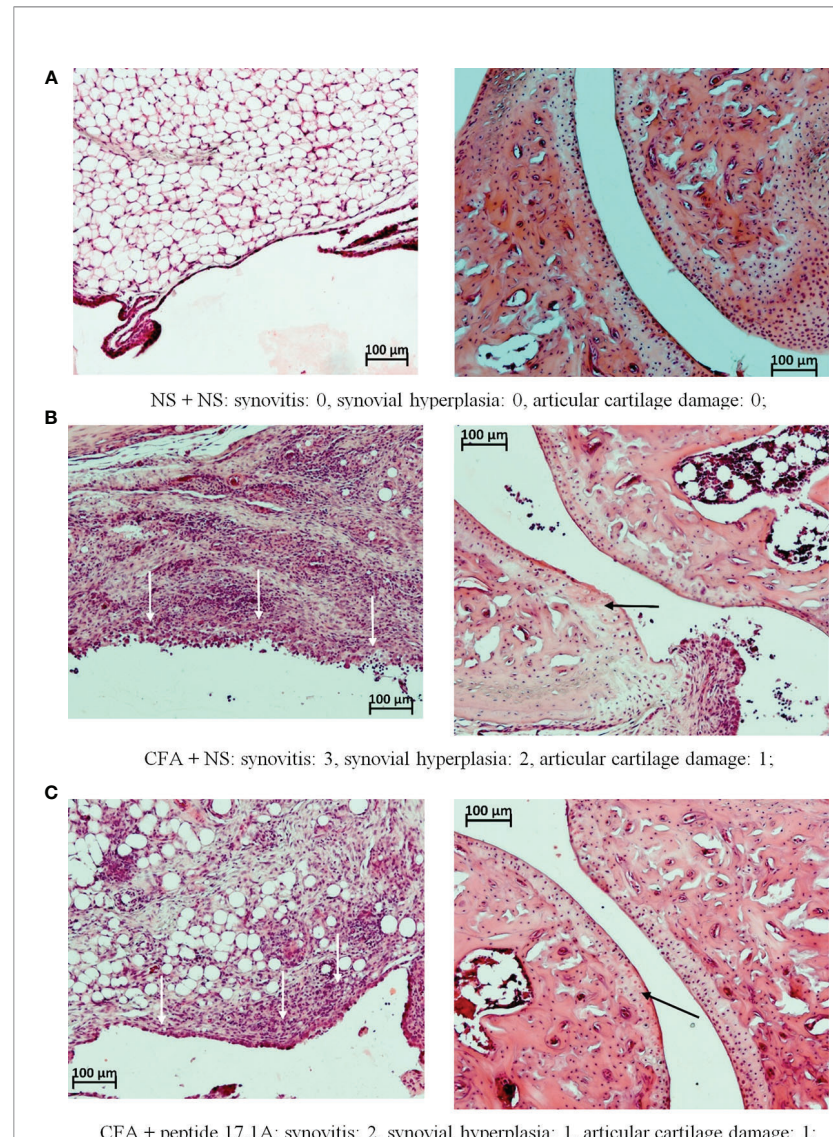

CFA + peptide 17.1A: synovitis: 2 , synovial hyperplasia: 1 , articular cartilage damage: 1 ;

D

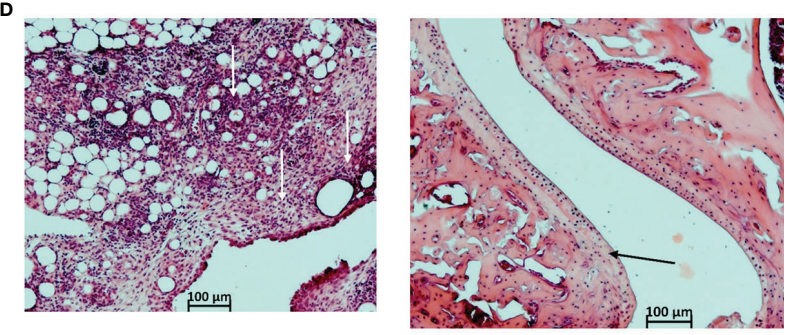

CFA + Norocarp: synovitis: 2 , synovial hyperplasia: 1 , articular cartilage damage: 1 ;
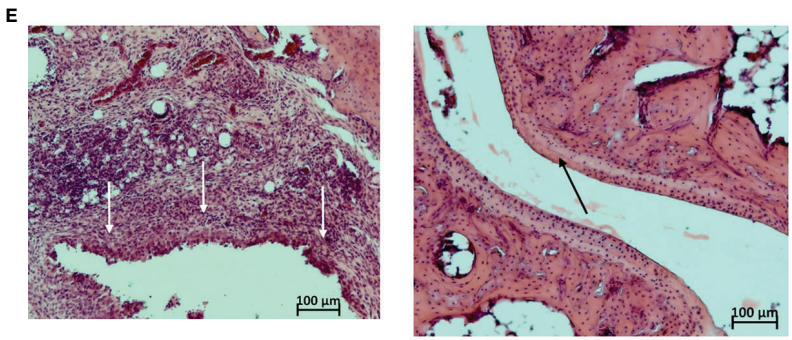

CFA + peptide 17.1: synovitis: 3 , synovial hyperplasia: 2 , articular cartilage damage: 1 .

FIGURE 8 | Fragments of the synovial membrane (left column) and the articular surfaces of hyaline cartilage (right column) of the left ankle joint of a mouse at day 21 in the control (A) and in the model of CFA-induced arthritis after injections of normal saline (B), peptide 17.1A (C), Norocarp (D), peptide 17.1 (E). The severity of synovitis and synovial hyperplasia (white arrows), as well as articular cartilage damage (black arrows) were assessed semiquantitatively. H\&E staining. Magnification 100x.
The course of CFA-induced arthritis in non-treated (control) mice from day 3 to day 21 was characterized by a gradually enhancing inflammatory response in soft tissues and expanding inflammatory infiltration from soft tissues into the synovial membrane followed by its hyperplasia, as well as by the development of inflammatory process in the neighboring bone tissues. Norocarp therapy exerted an anti-inflammatory effect, as it alleviated the clinical course of synovitis, inhibited cartilage and bone tissue destruction. The effectiveness of peptide 17.1A was similar to that of Norocarp, and the above mentioned trend was noticeable by day 10 and became obvious by day 21 of the observation period. Peptide 17.1A was superior to Norocarp as regards its protective effect for hard tissues of the joints. The other peptide, 17.1, demonstrated its effectiveness at day 10 of the study, but by day 21 it exhibited a lower activity against inflammation in soft tissues and destruction of bone tissues.

Peptide 17.1A demonstrated a higher anti-inflammatory activity, which can be explained by its structure. In contrast to a longer peptide 17.1 (17 amino acids), peptide 17.1A contains only eight amino acids. As known, short peptides can easier pass through the capillary walls $(25,26)$. Also, a low-molecular weight prevents entrapment of agents and allows them to pass easily through the lymphoid organs and tissues (27). Such features make it easier for peptide 17.1A to reach the site of inflammation and exhibit faster its topical anti-inflammatory effect. In addition, high affinity of peptide $17.1 \mathrm{~A}$ to the $\mathrm{TNF} \alpha$ receptor ensures its prolonged anti-inflammatory and, probably, analgesic activities. This assumption is supported by the changing temperature measurements in the affected limb (compared to the intact limb) and its reducing edema. After injection of the studied peptide, $\Delta \mathrm{t}$ was consistently decreasing throughout the experiment. At the same time, Norocarp, a drug used for comparison, caused the decrease in $\Delta t$ only for the first 3 days after CFA injection. Later, the temperature of the affected limb was rising. Thus, the studied peptide 17.1A can turn out to be a promising anti-inflammatory agent.

Limitation of study: in this study, we attempted a novel approach to the treatment of the abnormal action of TNF cytokine in a model of autoimmune arthritis. It is known that TNF can act as a cytokine and as a cytotoxic agent. As a cytokine, TNF stimulates proliferation of the cells and secretion of other cytokines, including also TNF, which potentiates proinflammatory immune response. As a cytotoxic agent, TNF can induce programmed cell death in cells. In both cases TNF binds with the receptor. TNF trimmer binds with the extracellular domain of TNFR1, followed by the aggregation of the receptor, the formation of an intracellular death domain, and the induction of cytotoxic processes. Described in this work peptides 17.1 and 17.1, as well as full-size Tag7, bind to the extracellular part of TNFR1, but do not lead to its aggregation and induction of cell death. We believe that the specificity of the inhibition of the cytotoxic activity of TNF under the action of peptide 17.1A consists in its competition with TNF for binding to TNFR1 on the cell surface. In previous studies, we have shown that TNF displaces peptide 17.1 from the complex with TNFR1 (13). 
This mechanism is the key difference between used nowadays therapeutic agents such as Infliximab and proposed in these work agents. At present time, the only drugs that are in clinical practice or in clinical trials to block $\mathrm{TNF} \alpha$ are biologicals, protein-based drugs, either antibody to TNF $\alpha$ or based on TNF $\alpha$ receptors (e.g. linked to Fc dimers).

Today, one of the approved drugs during treatment of rheumatoid arthritis by humans was Chimeric Monoclonal Anti-TNF ${ }^{\circledR}$, Infliximab (Remicade ${ }^{\mathrm{TM}}$ ) in the United States and Europe (28). This antibody was chimerized and is a mouse Fc, human IgG1, antibody of high affinity and neutralizing capacity with the potential for effector functions on human cells (29). Monoclonal antibodies and decoy receptors target TNF themselves and are trying to decrease its effective concentration. These agents have the major advantage of specificity (30), but have significant disadvantages, including the need for repeated injection and their relative high cost compared to small organic chemical drugs (31-33). Moreover, as our colleagues proved Infliximab neutralizes human but not murine TNF, which makes it difficult to use it as a TNF biotherapy in CFA-induced arthritis to animals $(34,35)$.

Used in this work peptides not only can decrease effective concentration of TNF via disruption of additional TNF production, but also protect the cells from TNF induced cell death, decreasing collateral damage of TNF abnormal functioning. Furthermore, the peptides used in this work have several advantages over high molecular weight drugs, used for therapy. They are the surface peptides of the protein, presented in the blood. Hence, the development of allergic or autoimmune reactions and toxicity is highly unlikely.

Our in vitro studies show that used peptides possess inhibitory effect at nanomolar concentrations which suggests their affinity to the TNFR1 receptor comparable to TNF. Moreover, due to their low molecular weight it seems likely that these peptides will have advantages in penetration of biological barriers such as joint bag and blood-brain barrier. Thus, we hope that suggested peptides are promising agents for treatment of joint bag inflammation.

To summarize, we demonstrated that short peptide fragments of PLYRP1 protein are capable of inhibiting the TNF $\alpha$ cytotoxic activity in vitro and exhibiting protective effect against TNF $\alpha$ mediated diseases in vivo. It was found that they prevent soft and bone tissue damages and reduce inflammation. The studied

\section{REFERENCES}

1. Zelová H, Hošek J. TNF- $\alpha$ Signalling and Inflammation: Interactions Between Old Acquaintances. Inflamm Res (2013) 62:641-51. doi: 10.1007/s00011-013-0633-0

2. Liu Y, Yin H, Zhao M, Lu Q. TLR2 and TLR4 in Autoimmune Diseases: A Comprehensive Review. Clin Rev Allergy Immunol (2014) 47:136-47. doi: 10.1007/s12016-013-8402-y

3. Sedger LM, McDermott MF. TNF and TNF-Receptors: From Mediators of Cell Death and Inflammation to Therapeutic Giants - Past, Present and Future. Cytokine Growth Factor Rev (2014) 25:453-72. doi: 10.1016/j.cytogfr.2014.07.016

4. Holbrook J, Lara-Reyna S, Jarosz-Griffiths H, McDermott M. Tumour Necrosis Factor Signalling in Health and Disease. F1000Res (2019) 8:F1000, Faculty Rev-111. doi: 10.12688/f1000research.17023.1 peptides could be used in other models of autoimmune diseases, e.g. systemic lupus erythematosus (SLE).

\section{DATA AVAILABILITY STATEMENT}

The original contributions presented in the study are included in the article/Supplementary Material. Further inquiries can be directed to the corresponding author.

\section{ETHICS STATEMENT}

The animal study was reviewed and approved by the Institutional Animal Care and Use Committee (IACUC), Shemyakin and Ovchinnikov Institute of Bioorganic Chemistry Russian Academy of Science.

\section{AUTHOR CONTRIBUTIONS}

Conceptualization, GT, LS, and DY. Methodology, TS, AC, and VK. Software, DY. Validation, LS and DY. Formal analysis, LS and DY. Investigation, ER, TS, GT, VK, AC, AG, LS, and DY. Resources, GT and AG. Data Curation, LS, AC, and DY. Writing-Original draft preparation, LS and AG. Writing - review and editing, LS, DY, AC, and GT. Supervision, GT. Project administration, LS and DY. Funding acquisition, LS. All authors contributed to the article and approved the submitted version.

\section{FUNDING}

This work was supported by a grant from the Russian Foundation of Basic Research (grant no. 20-04-60059\20).

\section{SUPPLEMENTARY MATERIAL}

The Supplementary Material for this article can be found online at: https://www.frontiersin.org/articles/10.3389/fimmu.2021. 622471/full\#supplementary-material

5. Bradley JR. TNF-Mediated Inflammatory Disease. J Pathol (2008) 214:149 60. doi: 10.1002/path.2287

6. Tracey D, Klareskog L, Sasso EH, Salfeld JG, Tak PP. Tumor Necrosis Factor Antagonist Mechanisms of Action: A Comprehensive Review. Pharmacol Ther (2008) 117:244-79. doi: 10.1016/j.pharmthera.2007.10.001

7. Yashin DV, Ivanova OK, Soshnikova NV, Sheludchenkov AA, Romanova EA, Dukhanina EA, et al. Tag7 (PGLYRP1) in Complex With Hsp70 Induces Alternative Cytotoxic Processes in Tumor Cells Via TNFR1 Receptor. J Biol Chem (2015) 290:21724-31. doi: 10.1074/jbc.M115.639732

8. Kang D, Liu G, Lundström A, Gelius E, Steiner H. A Peptidoglycan Recognition Protein in Innate Immunity Conserved From Insects to Humans. Proc Natl Acad Sci USA (1998) 95:10078-82. doi: 10.1073/pnas.95.17.10078

9. Liu C, Gelius E, Liu G, Steiner H, Dziarski R. Mammalian Peptidoglycan Recognition Protein Binds Peptidoglycan With High Affinity, Is Expressed in 
Neutrophils, and Inhibits Bacterial Growth. J Biol Chem (2000) 275:24490-9. doi: $10.1074 /$ jbc.M001239200

10. Dukhanina EA, Lukyanova TI, Romanova EA, Guerriero V, Gnuchev NV, Georgiev GP, et al. A New Role for PGRP-S (Tag7) in Immune Defense: Lymphocyte Migration Is Induced by a Chemoattractant Complex of Tag7 With Mts1. Cell Cycle (2015) 14:3635-43. doi: 10.1080/15384101.2015.1104440

11. Sharapova TN, Ivanova OK, Soshnikova NV, Romanova EA, Sashchenko LP, Yashin DV. Innate Immunity Protein Tag7 Induces Three Distinct Populations of Cytotoxic Cells That Use Different Mechanisms to Exhibit Their Antitumor Activity on Human Leukocyte Antigen-Deficient Cancer Cells. J Innate Immun (2017) 9:598-608. doi: 10.1159/000479382

12. Sashchenko LP, Dukhanina EA, Yashin DV, Shatalov YV, Romanova EA, Korobko EV, et al. Peptidoglycan Recognition Protein Tag7 Forms a Cytotoxic Complex With Heat Shock Protein 70 in Solution and in Lymphocytes. J Biol Chem (2004) 279:2117-24. doi: 10.1074/jbc.M307513200

13. Romanova EA, Sharapova TN, Telegin GB, Minakov AN, Chernov AS, Ivanova OK, et al. a 12-Mer Peptide of Tag7 (PGLYRP1) Forms a Cytotoxic Complex With Hsp70 and Inhibits TNF-Alpha Induced Cell Death. Cells (2020) 9:488. doi: 10.3390/cells9020488

14. Li D. Strategic Approaches to Optimizing Peptide ADME Properties. AAPS J (2015) 17:134-43. doi: 10.1208/s12248-014-9687-3

15. Shuster AM, Gololobov GV, Kvashuk OA, Bogomolova AE, Smirnov IV, Gabibov AG. DNA Hydrolyzing Autoantibodies. Science (1992) 256:665-7. doi: 10.1126/science.1585181

16. Altin JG, Pagler EB. A One-Step Procedure for Biotinylation and Chemical CrossLinking of Lymphocyte Surface and Intracellular Membrane-Associated Molecules. Anal Biochem (1995) 224:382-9. doi: 10.1006/abio.1995.1054

17. Lim MA, Louie B, Ford D, Heath K, Cha P, Betts-Lacroix J, et al. Schaevitz Development of the Digital Arthritis Index, a Novel Metric to Measure Disease Parameters in a Rat Model of Rheumatoid Arthritis. Front Pharmacol (2017) 8:818. doi: 10.3389/fphar.2017.00818

18. Samud AW, Asmawi MZ, Sharma JN, Yusof AP. Anti-inflammatory Activity of Crinum Asiaticum Plant and Its Effect on Bradykinin-Induced Contractions on Isolated Uterus. Immunopharmacology (1999) 43:311-6. doi: 10.1016/s0162-3109(99)00132-0

19. Andreev-Andrievskiy AA, Kolosova NG, Stefanova NA, Lovat MV, Egorov MV, Manskikh VN, et al. Efficacy of Mitochondrial Antioxidant Plastoquinonyl-Decyl-Triphenylphosphonium Bromide (Skq1) in the Rat Model of Autoimmune Arthritis. Oxid Med Cell Longev (2016) 8703645:19. doi: $10.1155 / 2016 / 8703645$

20. Sharapova TN, Romanova EA, Soshnikova NV, Belogurov AA, Lomakin YA, Sashchenko LP, et al. Autoantibodies From SLE Patients Induce Programmed Cell Death in Murine Fibroblast Cells Through Interaction With TNFR1 Receptor. Sci Rep (2020) 10:11144. doi: 10.1038/s41598-020-68088-x

21. Hawkins P, Armstrong R, Boden T, Garside P, Knight K, Lilley E, et al. Applying Refinement to the Use of Mice and Rats in Rheumatoid Arthritis Research. Inflammopharmacology (2015) 23:131-50. doi: 10.1007/s10787015-0241-4

22. Mausset-Bonnefont AL, Cren M, Vicente R, Quentin J, Jorgensen C, Apparailly F, et al. Arthritis Sensory and Motor Scale: Predicting Functional Deficits From the Clinical Score in Collagen-Induced Arthritis. Arthritis Res Ther (2019) 21:264. doi: 10.1186/s13075-019-2047-z

23. Yashin DV, Romanova EA, Ivanova OK, Sashchenko LP. The Tag7-Hsp70 Cytotoxic Complex Induces Tumor Cell Necroptosis Via Permeabilisation of
Lysosomes and Mitochondria. Biochimie (2016) 123:32-6. doi: 10.1016/ j.biochi.2016.01.007

24. Fischer R, Kontermann RE, Pfizenmaier K. Selective Targeting of TNF Receptors as a Novel Therapeutic Approach. Front Cell Dev Biol (2020) 8:401. doi: $10.3389 /$ fcell.2020.00401

25. Simionescu N, Siminoescu M, Palade GE. Permeability of Muscle Capillaries to Small Heme-Peptides. Evidence for the Existence of Patent Transendothelial Channels. J Cell Biol (1975) 64:586-607. doi: 10.1083/ jcb.64.3.586

26. Ellert-Miklaszewska A, Poleszak K, Kaminska B. Short Peptides Interfering With Signaling Pathways as New Therapeutic Tools for Cancer Treatment. Future Med Chem (2016) 9:199-221. doi: 10.4155/fmc-2016-0189

27. Clement CC, Wang W, Dzieciatkowska M, Cortese M, Hansen KC, Becerra A, et al. Quantitative Profiling of the Lymph Node Clearance Capacity. Sci Rep (2018) 8:11253. doi: 10.1038/s41598-018-29614-0

28. Elliott MJ, Maini RN, Feldmann M, Long-Fox A, Charles P, Katsikis P, et al. Treatment of Rheumatoid Arthritis With Chimeric Monoclonal Antibodies to Tumor Necrosis Factor Alpha. Arthritis Rheumatol (1993) 36:1681-90. doi: 10.1002/art.1780361206

29. Knight DM, Trinh H, Le J, Siegel S, Shealy D, McDonough M, et al. Construction and Initial Characterization of a Mouse-Human Chimeric Anti-TNF Antibody. Mol Immunol (1993) 30:1443-53. doi: 10.1016/01615890(93)90106-1

30. Breedveld FC. Therapeutic Monoclonal Antibodies. Lancet (2000) 26;355 (9205):735-40. doi: 10.1016/s0140-6736(00)01034-5

31. Tugwell P. Pharmacoeconomics of Drug Therapy for Rheumatoid Arthritis. Rheumatology (2000) 39(Suppl. 1):43-7. doi: 10.1093/oxfordjournals. rheumatology.a031494

32. Mohler KM, Torrence DS, Smith CA. Soluble Tumour Necrosis Factor (TNF) Receptors are Effective Therapeutic Agents in Lethal Endotoxemia and Function Simultaneously as Both TNF Carriers and TNF Antagonists. J Immunol (1993) 151:1548-61.

33. Lesslauer W, Tabuchi H, Gentz R, Brockhaus M, Schlaeger EJ, Grau G, et al. Recombinant Soluble TNF Receptor Proteins Protect Mice From LPS-Induced Lethality. Eur J Immunol (1991) 21:2883-86. doi: 10.1002/eji.1830211134

34. Winsauer C, Kruglov AA, Chashchina AA, Drutskaya MS, Nedospasov SA. Cellular Sources of Pathogenic and Protective TNF and Experimental Strategies Based on Utilization of TNF Humanized Mice. Cytokine Growth Factor Rev (2104) 25(2):115-23. doi: 10.1016/j.cytogfr.2013.12.005

35. Kruglov AA, Nedospasov SA. Comment on "Experimental Arthritis Triggers Periodontal Disease in Mice: Involvement of TNF- $\alpha$ and the Oral Microbiota". J Immunol (2012) 188(1):4-5. doi: 10.4049/jimmunol.1190080

Conflict of Interest: The authors declare that the research was conducted in the absence of any commercial or financial relationships that could be construed as a potential conflict of interest.

Copyright $\odot 2021$ Telegin, Chernov, Kazakov, Romanova, Sharapova, Yashin, Gabibov and Sashchenko. This is an open-access article distributed under the terms of the Creative Commons Attribution License (CC BY). The use, distribution or reproduction in other forums is permitted, provided the original author(s) and the copyright owner(s) are credited and that the original publication in this journal is cited, in accordance with accepted academic practice. No use, distribution or reproduction is permitted which does not comply with these terms. 